\title{
湿式球形造粒時の擋拌動力
}

\section{The Power Requirement of an Agitating Impeller in Spherical Agglomeration in a Tank}

\author{
高 瀬 均*, 左 波 一 彦* \\ Hitoshi TAKASE*, Kazuhiko SANAMI*
}

\begin{abstract}
The power requirement characteristics of an agitating impeller in a spherical agglomeration tank were investigated. Two spherical agglomeration systems were adopted in the experiment : coal-heavy oil-water : and $\mathrm{CaCO}_{3}-\mathrm{CaCl}_{2}$ aq. soln. ${ }^{-} \mathrm{CCl}_{4}$. The uniform suspension in the tank was maintained through the agglomeration process.

During the progress of spherical agglomeration, the particle size distribution of agglomerates shifted to the large size range, and the compaction of the agglomerates was promoted. The power requirement increased with increasing mean agglomerate size, with the bulk volume of agglomerates in the slurry, and with the density of the agglomerate.

The empirical equation, which shows the relationship between the ratio of the power number in the spherical agglomeration to that in the agitation of the disperse medium without agglomerates and the suspending conditions of the agglomerates, was obtained.
\end{abstract}

Key Words : Spherical Agglomeration, Agitation, Power Number, Suspension, Particle Size Distribution

\section{1. 緒 言}

湿式球形造粒法 ${ }^{1,2)}$ では, 微細粒子を鞔濁させた液中 に分散媒と非混和性の架橋剂を添加して撹拌し，架橋 剤を介して馝濁粒子を凝集，さらにこれらを合一，圧 密させて造粒粒子が得られる。この時, 分散相である 造粒粒子の粒子径分布，造粒粒子密度などが造粒の進 行につれて連続的に変化する。このような造粒粒子の 特性值の変化は, 造粒粒子を含む㦟濁液の搅拌動力に も影響を与えると考えられる。

これまで, 均一固体粒子㲜濁液の擋拌動力特性は, 主に懸濁粒子径の大きさにより二つのパターンに分け られてきた。一つは㲘濁粒子の平均径が $0.42 \mathrm{~mm}$ 以下, 液中における粒子体積分率が 0.15 以下の, 微小粒子か つ低粒子濃度の場合である。このとき，擋拌動力は液 に対する敩拌動力推算式において, 液密度の代わりに 慜濁液の平均密度を代入することによりほぼ推算でき $ろ^{3,4)}$ 。これに対し，より粒子径の大きな粒子を含む称

1996年 6 月 3日受付

* 富山大学工学部物質工学科

( T930 富山市五福 3190) TEL. 0764-45-6830

Dept. of Materials Sci. and Eng., Toyama Univ.

(3190 Gofuku, Toyama-shi, 930)
濁液を搅拌する場合，敩拌動力は上記の方法による推 算值よりも大きくなる5)。この原因の一つとしては, 粒子径の増大につれて, 粒子と撹拌翼面との衝突によ る抵抗が大きくなることが指摘されている。一方, 著 者ら ${ }^{6)}$ は, 液と同密度の平均粒子径が $0.46 \sim 2.19 \mathrm{~mm}$ の 粗粒子を㦟濁させたスラリ一の搅拌動力特性について 検討し, 擋拌動力が愁濁粒子の液中におけるかさ体積 と平均粒子径により大きく影響されることを示してい る。

著者らは既報》において, 均一䋰濁状態の搅拌槽造 粒器内での湿式球形造粒時の搅拌トルクについて検討 し, 敩拌トルクが造粒の進行につれて変化することを 述べた。そして, 搅拌トルクの変化が造粒進行の一つ の指標となりうること, また平均造粒粒子径が $0.5 \mathrm{~mm}$ を超えるようになると, 造粒粒子径の増大につ れての搅拌トルクの増大が顕著となることを示した。 しかし，撹拌動力特性とこれに大きく影響すると考え られる造粒粒子の種々の特性值との定量的関係につい ては，ほとんど明かにしていない。本論文では，湿式 球形造粒においては，造粒粒子が分散媒中の懸濁粒子

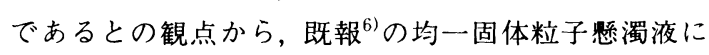
対する敩拌動力特性の検討結果などをもとに, 造粒時 
の撹拌動力変化と造粒粒子の粒子径分布, 液中におけ る体積分率, 密度などとの関係について検討を行っ た。

\section{2. 実験装置および実験方法}

湿式球形造粒を, Fig. 1に示す円筒型撹拌槽造粒器 内で行った。造粒器は内径 $10 \mathrm{~cm}$ で, 器壁には幅 $1.4 \mathrm{~cm}$ の邪魔板が 4 枚設けられている。撹拌翼は, 旸根径 $6 \mathrm{~cm}$ ，旸根幅 $1 \mathrm{~cm}$ の櫂型 4 枚旸根で，その中心を器底 から5cmの位置に置いた。Tables 1，2に，本論文で

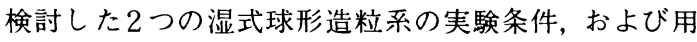
いた試料の物性を示す。このうち，炭酸カルシウム一 20wt \%-塩化カルシウム水溶液一四塩化炭素系(以後, 炭酸カルシウム造粒系と呼ぶの造粒については，既 報7)で報告した実験結果をもとに造粒粒子に関する特 性值, 動力数などの值を算出し, その結果より造粒時 の敩拌動力特性について検討を行った。このため，炭 酸カルシウム造粒系のみに適用される実験方法につい ての説明は，ここでは省略することにする。

試料粒子を㦟濁させた液中に，架橋剂を10秒間で添 加して湿式球形造粒を開始した。架橋剂添加開始時 を，造粒時間 $t_{\mathrm{a}}=0 \min$ とした。造粒時の擋拌動力 $P$ お よび造粒粒子に関する特性值の測定を， $t_{\mathrm{a}} \geqq 1.5 \mathrm{~min} の$

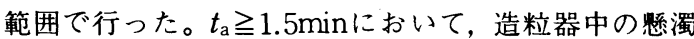

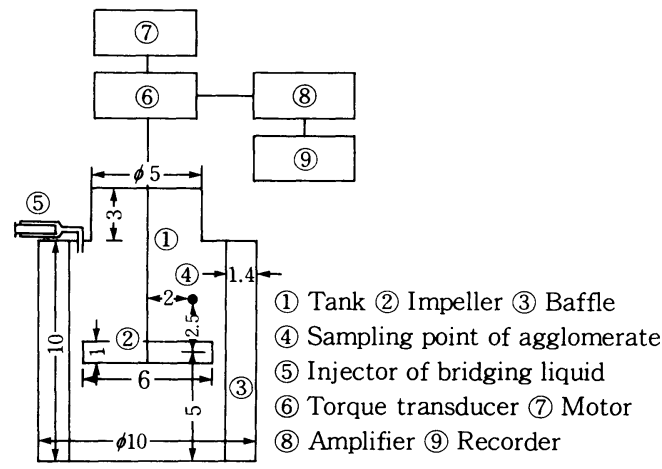

Fig. 1 Experimental apparatus (Unit $\mathrm{cm}$ )
液を固・液分離し, 分離液中に含まれる架橋剂量の測 定を次のように行った。水中の重油量をJIS K 0102 「工場排水試験方法」のn一ヘキサン法により測定し, 四塩化炭素中の塩化カルシウム水溶液量を分離液の密 度測定の結果から求めた。その結果, $t_{\mathrm{a}} \geqq 1.5 \mathrm{~min} に お ~$ いては，添加架橋剂のほぼすべてが造粒粒子中に含ま れていることを確認した。造粒粒子採取点より造粒粒 子を採取し，これを乾燥後，篩分け法により粒子径分 布を測定した。

石炭粒子一重油一水系(以後, 石炭造粒系と呼ぶ)に おいて, 造粒粒子中の水分量の測定を以下の方法で行 つた。所定時間の敩拌後, 造粒器内の㦟濁液を底部に 100 メッシュの金網を設けた内径 $65 \mathrm{~mm}$ の円筒器内に

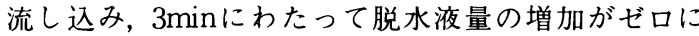
なるまで通気脱水を行った。その後, 器内の造粒粒子 層中の全水分重量 $w_{\mathrm{t}}$ ， JIS K $2275\ulcorner$ 原油及び石油製 品水分試験方法」の蒸留法により測定し, 造粒粒子径 の大きさとの関係から造粒粒子外部の水分重量 $w_{\mathrm{o}}$ を 算出して ${ }^{8)}$, Eq. (1)により正味の造粒粒子中の水分重 量 $w_{\mathrm{i}}$ を求めた。この $w_{\mathrm{i}}$ の值は, 造粒粒子密度 $\rho_{\mathrm{a}}$ の算出 の際に，造粒粒子中の分散媒重量として用いられた。

$$
w_{\mathrm{i}}=w_{\mathrm{t}}-w_{\mathrm{o}}
$$

造粒器内の均一㤅濁状態の確認を, 既報 ${ }^{7)}$ と同様の方 法により行った。すなわち, 造粒を行った場合と同器

Table 2 Properties of materials

\begin{tabular}{lccc}
\hline & $\rho_{\mathrm{p}}\left(\mathrm{kg} / \mathrm{m}^{3}\right)$ & $d_{50}(\mathrm{~m})$ & \\
Coal powder & $1.53 \times 10^{3}$ & $2.18 \times 10^{-5}$ & \\
$\mathrm{CaCO}_{3}$ powder & $2.72 \times 10^{3}$ & $8.79 \times 10^{-6}$ & \\
\hline & $\rho\left(\mathrm{kg} / \mathrm{m}^{3}\right)$ & $\eta(\mathrm{mPa} \cdot \mathrm{s})$ & $T\left({ }^{\circ} \mathrm{C}\right)$ \\
Water & $1.00 \times 10^{3}$ & 0.80 & 30 \\
Heavy oil & $8.69 \times 10^{2}$ & 14.8 & \\
& & & 40 \\
$\mathrm{CCl}_{4}$ & $1.56 \times 10^{3}$ & 0.74 & \\
$20-$ wt $\%-\mathrm{CaCl}_{2}$ & $1.16 \times 10^{3}$ & 1.25 & \\
aq. soln. & & & \\
\hline
\end{tabular}

Table 1 Experimental conditions

\begin{tabular}{|c|c|c|c|c|c|c|c|}
\hline Powder & $\begin{array}{l}\text { Disperse } \\
\text { medium }\end{array}$ & $\begin{array}{l}\text { Bridging } \\
\text { liquid }\end{array}$ & $\begin{array}{c}c \\
\left(\mathrm{vol}^{\circ} \%\right)\end{array}$ & $\begin{array}{c}r \\
(-)\end{array}$ & $\begin{array}{c}T \\
\left({ }^{\circ} \mathrm{C}\right)\end{array}$ & $\begin{array}{c}n \\
\left(s^{-1}\right)\end{array}$ & $\begin{array}{c}t_{\mathrm{al}} \\
(\mathrm{min})\end{array}$ \\
\hline Coal & Water & Heavy oil & $\begin{array}{r}8 \\
12 \\
\end{array}$ & $\begin{array}{l}0.45 \\
0.50 \\
0.55\end{array}$ & 30 & 25 & 20 \\
\hline $\mathrm{CaCO}_{3}$ & $\mathrm{CCl}_{4}$ & $\begin{array}{l}20 \mathrm{wt} \%-\mathrm{CaCl}_{2} \\
\text { aq. soln. }\end{array}$ & 12 & $\begin{array}{l}0.30 \\
0.35 \\
0.40\end{array}$ & 40 & 25 & 10 \\
\hline
\end{tabular}




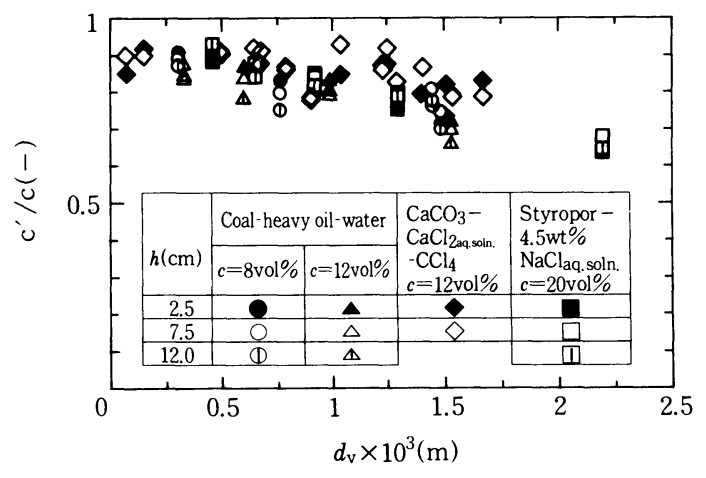

Fig. 2 Examination of homogeneous suspension of agglomerates in agitated tank

内に液と同密度のモデル粒子を懸濁させて均一㦟濁状 態とした場合について, 器底よりの高さ $h=2.5,7.5$, $12.0 \mathrm{~cm}^{* 1)}$ の位置の器壁に設けた, 内径 $6 \mathrm{~mm}$ の採取口 よりそれぞれ㦟濁液を採取し，そこに含まれる固体粒 子濃度を相互に比較することにより, 造粒粒子の慗濁 状態の確認を行った。Fig. 2に, 懸濁液採取実験の結 果を示す*2)。採取榡濁液中の固体粒子濃度 $c^{\prime}$ と造粒器 内の平均固体粒子濃度 $c$ の比 $c^{\prime} / c$ の值は，（㦟濁粒子 径)/(採取口径)の比に影響されて, 㦟濁粒子の体積 平均径 $d_{\mathrm{v}}$ が大きくなるにつれて減少するが, 固・液が 同密度で均一䜿濁状態となっている球形モデル粒子 (スチロポール粒子, $\rho=1.03 \times 10^{3} \mathrm{~kg} / \mathrm{m}^{3}$ ) - $4.5 \mathrm{wt} \%$ $\mathrm{NaCl}$ 水溶液 $\left(30^{\circ} \mathrm{C}, \rho_{\mathrm{d}}=1.03 \times 10^{3} \mathrm{~kg} / \mathrm{m}^{3}, \quad \eta_{\mathrm{d}}=0.86\right.$ $\mathrm{mPa} \cdot \mathrm{s})$ 系に対する $c^{\prime} / c$ と各造粒系に対する $c^{\prime} / c$ は, ほぼ同じ值を示している。また, 態濁粒子径が同じ場 合，各採取口高さに対する $c^{\prime} / c$ もほぼ同じ值となって いる。これより, 湿式球形造粒時においても, 造粒器 内では造粒粒子の均一䍩濁状態が保たれているものと 考えられる。

\section{3. 実験結果および考察}

\section{1 湿式球形造粒の進行と摚拌動力の変化}

Fig. 3に, 造粒の進行に伴う造粒粒子の粒子径分布 の変化を示す。粒子径分布は, 造粒時間の経過につれ て大粒子径側に移行するが, 造粒初期において炭酸力 ルシウム造粒系の方が石炭造粒系に比較して分布幅が 広くなる傾向が見られる。また，造粒時間 $t_{\mathrm{a}} \geqq 1.5 \mathrm{~min}$ においては，いずれの造粒条件においても平均造粒粒 子径 $d_{\mathrm{v}} \geqq 2.7 \times 10^{-4} \mathrm{~m}$ となった。このような粒子径範

*1) $h=12.0 \mathrm{~cm}$ の採取口は, 造粒器上部の内径 $5 \mathrm{~cm}$ の円筒部器 壁に設けられた。

*2）炭酸カルシウム造粒系に対しては, $h=2.5,7.5 \mathrm{~cm}$ の採取口 を使って行われた既報7)の結果を示した。

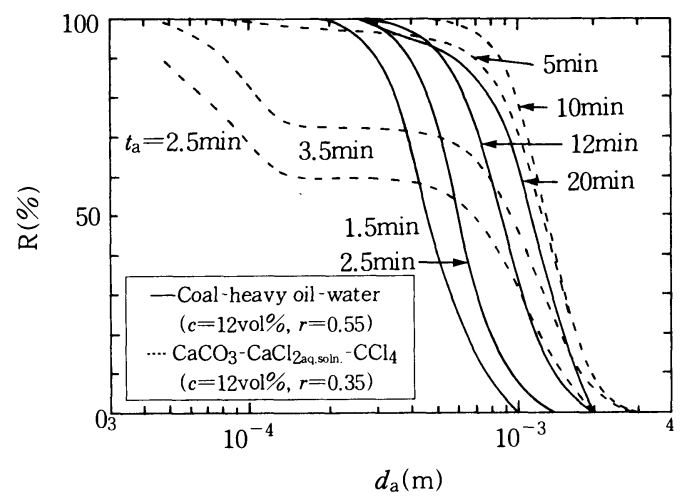

Fig. 3 Particle size distribution of agglomerates

囲では, 㦟濁造粒粒子間に動く凝集力は他の外力に比 較して相対的に小さくなり，造粒は主に液の乱れや剪 断流れなどによる造粒粒子同士の衝突により進行する ものと考えられる。そして, 個々の造粒粒子は二ュ一 トン流体である分散媒中でよく分散した状態で㗭濁し ていると考えられる。

Fig. 4 に, 撹拌動力 $P$ の測定結果を示す。図中に矢 印で示した $P_{\text {water, }} P_{\mathrm{CCl} 4}$ は, 各造粒系での分散媒である 水, および四塩化炭素のみを造粒器内に入れて搅拌し た際の摇拌動力である。造粒時の撹拌動力は, 分散媒 のみを撹拌する場合より大きく，またFig. 3との比較 より，造粒の進行につれて増大することがわかる。

Fig. 5に, Eqs(2),（3)で定義される分散媒のみを 撹拌した場合の動力数 $N_{\mathrm{p} 0}$ と造粒時の動力数 $N_{\mathrm{p}}$ との比 $N_{\mathrm{p}} / N_{\mathrm{p} 0}$ の経時変化を示す。

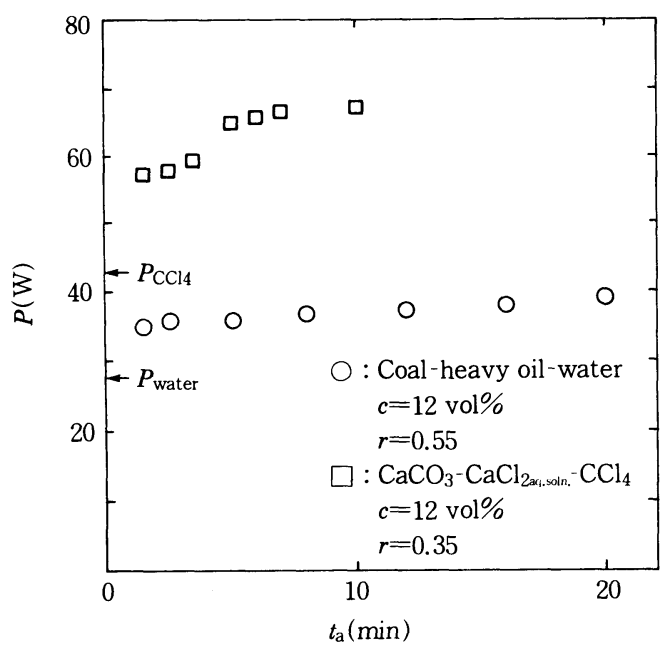

Fig. 4 Change in power requirement of impeller with the progress of spherical agglomeration 


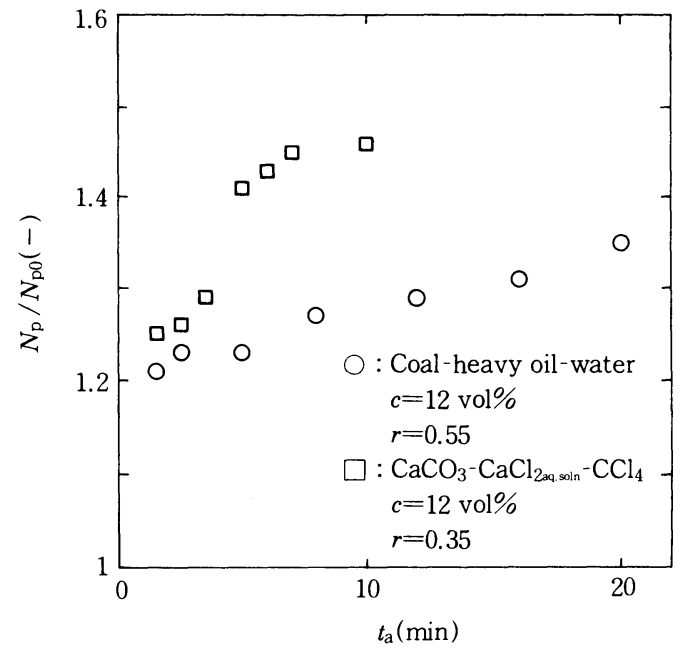

Fig. 5 Relationship between $N_{\mathrm{p}} / N_{\mathrm{p} 0}$ and $t_{\mathrm{a}}$

$$
\begin{aligned}
& N_{\mathrm{p} 0}=\frac{P}{\rho_{\mathrm{d}} n^{3} d_{\mathrm{i}}^{5}} \\
& N_{\mathrm{p}}=\frac{P}{\rho_{\mathrm{s}} n^{3} d_{\mathrm{i}}{ }^{5}}
\end{aligned}
$$

ここで， $\rho_{\mathrm{s}}$ は造粒粒子を含む㦟濁液の平均密度で, 造 粒粒子密度 $\rho_{\mathrm{a}}$ およ゙造粒粒子の㦟濁液中での体積分率 $\Phi^{* 3)}$ より, Eq. (4)で求められる。

$\rho_{\mathrm{s}}=\rho_{\mathrm{d}}(1-\Phi)+\rho_{\mathrm{a}} \Phi$

$\rho_{\mathrm{a}}, \Phi$ Ф，それぞれ次式で求められた。

$$
\begin{gathered}
\rho_{\mathrm{a}}=\frac{M_{\mathrm{p}}+M_{\mathrm{b}}+M_{\mathrm{d}}}{V_{\mathrm{p}}+V_{\mathrm{b}}+V_{\mathrm{d}}} \\
\Phi=\frac{V_{\mathrm{p}}+V_{\mathrm{b}}+V_{\mathrm{d}}}{V_{\mathrm{t}}}
\end{gathered}
$$

ここで, $M_{\mathrm{p}}, V_{\mathrm{p}}, M_{\mathrm{b}}, V_{\mathrm{b}}, M_{\mathrm{d}}, V_{\mathrm{d}}$ は, それぞれ造粒 粒子中に含まれる固体粒子, 架橋剂, 分散媒の重量お よび体積であり， $V_{\mathrm{t}}$ は造粒器内の全愁濁液体積であ る。

Fig. 5において, $N_{\mathrm{p}} / N_{\mathrm{p} 0}$ は 1 より大きく, 時間の経 過とともにその值が増大している。二つの分散媒に対 する動力数 $N_{\mathrm{p} 0}$ は，いずれも 2.26 と同じ值となった。 これは, 水, 四塩化炭素がともに二ュートン流体であ り, これらの液を $n=25 \mathrm{~s}^{-1}$ で撹拌すると, 搅拌レイノ ルズ数 $N_{\mathrm{Re}}$ がそれぞれ $1.13 \times 10^{5}, 1.90 \times 10^{5}$ となり, 造 粒器内がともに乱流撹拌状態となるためと考えられる。

*3）本論文では, 内部に試料固体粒子, 架橋剂, 分散媒を含む 造粒粒子の毀濁液中での体積割合を，体積分率 $($-)で示し た。
すなわち, $N_{\mathrm{p}} / N_{\mathrm{p} 0}$ の変化は $N_{\mathrm{p}}$ の変化に対応しており， $N_{\mathrm{p}} / N_{\mathrm{p} 0}$ の值の 1 からのずれは，造粒粒子が液分子と 異なる大きさ, 密度を持つため, 両者の運動状態が異 なり，これが結果的に擋拌抵抗の増大につながって， $N_{\mathrm{p}}$ を増大させるためと考えられる。また， $N_{\mathrm{p}}$ の值は 炭酸カルシウム造粒系の場合の方が石炭造粒系の場合 に比較して大きな值となっている。Eq. (3)の定義よ り， $N_{\mathrm{p}}$ には愁濁液の平均密度の影響が含まれてい る。これより，両造粒系における $N_{\mathrm{p}}$ の違いには，それ ぞれの造粒粒子密度と分散媒密度との大きさの違いに よる影響が大きいと考えられる。固体粒子濃度 $c$ を 8 $\mathrm{vol} \%, 12 \mathrm{vol} \%$ と変えて行った石炭造粒系において, 架橋剂添加率 $r$ が同じ条件では， $N_{\mathrm{p}}$ は $c=12 \mathrm{vol} \%$ の場 合の方が大きな值となった。

\section{2 懸濁造粒粒子の種々の特性值}

湿式球形造粒時においては, Fig. 3に示すような造 粒粒子の粒子径分布の変化が起きると同時に, 造粒粒 子に関する他の特性值も変化する。

Fig. 6に，造粒時における造粒粒子の㦟濁液中にお ける体積分率 $\Phi$, 粒子充埴率 $\Phi_{\mathrm{p}}$ および密度 $\rho_{\mathrm{a}}$ の経時 変化を示す。造粒粒子をランダム充填した際の充填率 に相当する粒子充填率 $\Phi_{\mathrm{p}}$ を, 造粒粒子を球形と仮定 して，粒子径分布の測定結果よりLee ${ }^{9)} の$ 方法により 求めた。Fig. 6において，Фは時間 $t_{\mathrm{a}}$ の経過とともに 減少し，これに伴い $\rho_{\mathrm{a}}$ は増大している。これは，造粒 の進行につれて造粒粒子の圧密が進んでいることを示 しており，炭酸カルシウム造粒系において， $\Phi, \rho_{\mathrm{a}}$ の 変化がより大きくなっている。粒子充填率 $\Phi_{\mathrm{p}}$ は, 造
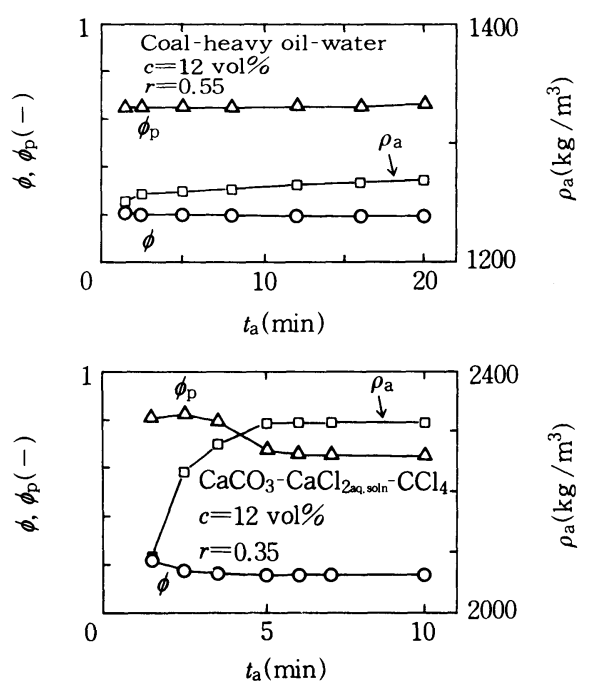

Fig. 6 Change in $\phi, \phi_{\mathrm{p}}$ and $\rho_{\mathrm{a}}$ with $t_{\mathrm{a}}$ 
粒初期において炭酸カルシウム造粒系の方が大きな值 となっている。これは, Fig. 3に示すように，造粒初 期において炭酸カルシウム造粒系の造粒粒子径分布の 幅が広くなることが原因である。造粒操作終了時 $\left(t_{\mathrm{a}}\right.$ $\left.=t_{\mathrm{al}}\right)$ において，両造粒系ともに $\Phi_{\mathrm{p}}$ は約 0.65 となった。

\section{3 㲜力数と懸濁造粒粒子の特性値との関係}

Fig. 5に見られる造粒時と分散媒搅拌時との動力数 の違いは, 分散媒中での愁濁造粒粒子の有無から生じ たものであり，また動力数の経時変化は造粒粒子の種 々の特性值の変化に伴って起こっているものと考えら れる。しかし，造粒時に同時かつ連続的に変化する造 粒粒子の各特性值の搅拌動力に対する影響を，それぞ れ個別に検討することはかなり困難である。そこで, 擋拌動力への造粒粒子の液中における体積分率 $\Phi$, 粒子充填率 $\Phi_{\mathrm{p}}$, および平均造粒粒子径の影響につい ては，モデル粒子を用いて検討した均一固体粒子愻濁 液に対して得られた搅拌動力と粒子㦟濁条件との関係 が，そのまま造粒時の搅拌にも適用できると考えて， 造粒時の擋拌動力特性について検討を行った。

著者らは既報6)において, $4.5 \mathrm{wt} \%-\mathrm{NaCl}$ 水溶液中に 同密度の球形モデル粒子(スチロポール粒子, $d_{\mathrm{p}}=$ $\left.0.46 \times 10^{-3} \sim 2.19 \times 10^{-3} \mathrm{~m}\right)$ を含む均一愁濁液の搅拌動 カについて検討し, 液基準の搅拌レイノルズ数 $N_{\mathrm{Re}}$ が $6.43 \times 10^{4} \leqq N_{\mathrm{Re}} \leqq 1.07 \times 10^{5}$ の範囲内において, 動力数 比 $N_{\mathrm{p}} / N_{\mathrm{p} 0}$ と粒子㦟濁条件との間にEqs. (7)，(8)の相 関式を得た。そして，実測值から計算される $N_{\mathrm{p}} / N_{\mathrm{p} 0}$ の值は，ほぼEq.（7)の右辺から求められる $N_{\mathrm{p}} / N_{\mathrm{p} 0}$ の 計算值 $\times(1 \pm 0.1)$ の範囲内となることを確かめてい る。

$$
\begin{aligned}
& N_{\mathrm{p}} / N_{\mathrm{p} 0}=\left(1-\Phi / \Phi_{\mathrm{p}}\right)^{\mathrm{A}} \\
& A=-12.3 d_{\mathrm{v}}^{0.49}
\end{aligned}
$$

Eqs. (7)，（8）は，㲜濁液単位体積当たりの㦟濁粒子の かさ体積 $\Phi / \Phi_{\mathrm{p}}$ の增大, または墼濁粒子の可動領域 に相当する值 $\left(1-\Phi / \Phi_{\mathrm{p}}\right)$ の減少につれて，また平均 粒子径が大きくなるにつれて, 動力数比 $N_{\mathrm{p}} / N_{\mathrm{p} 0}$ が大 きくなることを示している。

Fig. 7は, $N_{\mathrm{p}} / N_{\mathrm{p} 0}$ と造粒粒子の $\Phi, \Phi_{\mathrm{p}}, d_{\mathrm{v}}$ との関係 がEqs. (7)，（8）で表されるとして，( $\left.N_{\mathrm{p}} / N_{\mathrm{p} 0}\right) /(1-$ $\left.\Phi / \Phi_{\mathrm{p}}\right)^{\mathrm{A}}$ と $t_{\mathrm{a}}$ との関係を示したものである。図中にお いて, $\left(N_{\mathrm{p}} / N_{\mathrm{p} 0}\right) /\left(1-\Phi / \Phi_{\mathrm{p}}\right)^{\mathrm{A}}$ の值は, その大半が 1より大きくなり，一部において造粒初期に減少傾向 が見られるものの，全体としては造粒時間の経過とと もに增大する傾向が見られる。 $\left(N_{\mathrm{p}} / N_{\mathrm{p} 0}\right) /(1-\Phi /$ $\left.\Phi_{\mathrm{p}}\right)^{\mathrm{A}}$ の值には, 動力数に対する態濁造粒粒子の $\Phi, \Phi_{\mathrm{p}}$,

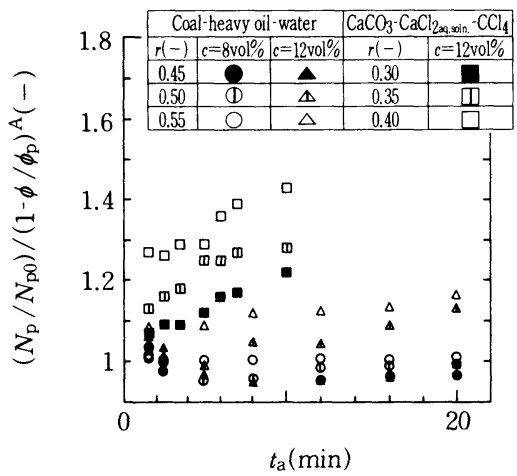

Fig. 7 Relationship between $\left(N_{\mathrm{p}} / N_{\mathrm{p} 0}\right) /\left(1-\phi / \phi_{\mathrm{p}}\right)^{\mathrm{A}}$ and $t_{\mathrm{a}}$

$d_{\mathrm{v}}$ の影響が考慮されていることから，このような造 粒の進行に伴う $\left(N_{\mathrm{p}} / N_{\mathrm{p} 0}\right) /\left(1-\Phi / \Phi_{\mathrm{p}}\right)^{\mathrm{A}}$ の值の増 大は，もう一つの造粒粒子に関する特性值である造粒 粒子密度の増大による影響が大きいものと考えられ る。

Fig. 8に, $\left(N_{\mathrm{p}} / N_{\mathrm{p} 0}\right) /\left(1-\Phi / \Phi_{\mathrm{p}}\right)^{\mathrm{A}}$ と造粒粒子と 分散媒との密度の比 $\rho_{\mathrm{a}} / \rho_{\mathrm{d}}$ との関係を示す。 $\left(N_{\mathrm{p}} /\right.$ $\left.N_{\mathrm{p} 0}\right) /\left(1-\Phi / \Phi_{\mathrm{p}}\right)^{\mathrm{A}}$ は, $\rho_{\mathrm{a}} / \rho_{\mathrm{d}}$ の值が大きくなるにつ れて増大している。本研究で造粒器として用いたよう な邪魔板付き搅拌槽内では, 愁濁液の流れ方向が急角 度で頻繁に変わる。特に，搅拌動力に大きく影響する 翼回転域付近においても流れ力向は急激に変化する。 造粒粒子と液の密度差の増大は, 流れ方向の急変箇所 などにおいて，慣性の影響などにより造粒粒子と液と の運動方向の違いを大きくする。このような造粒粒子 と液の運動方向の違いは, 造粒粒子の回転翼への衝 突，㦟濁液の造粒器内での流動性などに影響し，結果

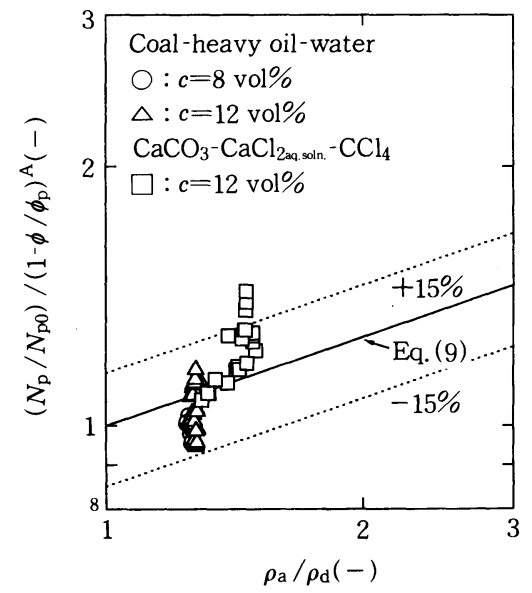

Fig. 8 Relationship between $\left(N_{\mathrm{p}} / N_{\mathrm{p} 0}\right) /\left(1-\phi / \phi_{\mathrm{p}}\right)^{\mathrm{A}}$ and $\rho_{\mathrm{a}} / \rho_{\alpha}$ 
的に擋拌動力の増大につながっているものと考えられ る。Fig. 8の結果より, 湿式球形造粒時の擋拌動力変 化と造粒粒子の㦟濁条件との関係は, Eqs. (9), (8)で 表される。

$$
\begin{aligned}
& N_{\mathrm{p}} / N_{\mathrm{p} 0}=\left(1-\Phi / \Phi_{\mathrm{p}}\right)^{\mathrm{A}}\left(\rho_{\mathrm{a}} / \rho_{\mathrm{d}}\right)^{0.34} \\
& A=-12.3 d_{\mathrm{v}}^{0.49}
\end{aligned}
$$

\section{4. 結言}

\section{湿式球形造粒時の撹拌動力特性と造粒粒子の榡濁条}

件との関係について，二つの造粒系による実験結果を もとに検討した。

均一盡濁状態の下で行われた湿式球形造粒時の動力 数は, 分散媒のみを搅拌した場合の動力数よりも大き く, 平均造粒粒子径, 愁濁液中における造粒粒子のか さ体積, 造粒粒子密度が大きくなるにつれて增大し た。

造粒時の動力数変化と造粒粒子の分散媒中における 悡濁条件との関係を表す実験式を得た。

\begin{tabular}{|c|c|c|c|c|}
\hline$A$ & : variable & $(-)$ & $t_{\mathrm{a}}$ & : agglomeration time \\
\hline \multirow[t]{2}{*}{ 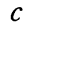 } & \multicolumn{2}{|c|}{ : volume concentration of powder in suspension } & $t_{\mathrm{al}}$ & : longest agglomeration time \\
\hline & & $\mathrm{vol} \%)$ & $V$ & : volume in agglomerates \\
\hline \multirow[t]{2}{*}{$c^{\prime}$} & \multicolumn{2}{|l|}{ : volume concentration of powder in sampled } & $V_{\mathrm{t}}$ & : volume of suspension in tank \\
\hline & suspension $\quad(v$ & $\operatorname{vol} \%)$ & $w_{\mathrm{i}}$ & : water weight in coal agglomerates \\
\hline$d_{\mathrm{a}}$ & : agglomerate diameter & $(\mathrm{m})$ & $w_{0}$ & : water weight in the outside of coal \\
\hline$d_{\mathrm{i}}$ & : impeller diameter & $(\mathrm{m})$ & & agglomerates \\
\hline$d_{\mathrm{p}}$ & : particle diameter & (m) & $w_{\mathrm{t}}$ & : total water weight in the packed bed of coal \\
\hline$d_{\mathrm{v}}$ & : volume mean diameter of agglomerate & $(\mathrm{m})$ & & agglomerates after air blow drainage $\quad(\mathrm{kg})$ \\
\hline$d_{50}$ & : $50 \%$ diameter of powder & $(\mathrm{m})$ & $\eta$ & \multirow{2}{*}{$\begin{array}{lr}: \text { viscosity } & (\mathrm{mPa} \cdot \mathrm{s}) \\
: \text { density } & \left(\mathrm{kg} \cdot \mathrm{m}^{-3}\right)\end{array}$} \\
\hline$h$ & \multicolumn{2}{|l|}{ : height of sampling tap of suspension from } & $\rho$ & \\
\hline & tank bottom & $(\mathrm{cm})$ & $\Phi$ & : volume fraction of agglomerates in suspension \\
\hline$M$ & : weight in agglomerates & $(\mathrm{kg})$ & & $(-)$ \\
\hline$N_{\mathrm{p}}$ & : power number $\left(=P /\left(\rho_{\mathrm{s}} n^{3} d_{\mathrm{i}}^{5}\right)\right)$ & $(-)$ & $\Phi_{\mathrm{p}}$ & : packing fraction of agglomerates \\
\hline$N_{\mathrm{p} 0}$ & : power number $\left(=P /\left(\rho_{\mathrm{d}} n^{3} d_{\mathrm{i}}^{5}\right)\right)$ & $(-)$ & & \\
\hline$N_{\operatorname{Re}}$ & : Reynolds number $\left(=\rho_{\mathrm{d}} n d_{\mathrm{i}}^{2} / \eta_{\mathrm{d}}\right)$ & $(-)$ & \multicolumn{2}{|c|}{$\langle$ Subscripts〉 } \\
\hline$n$ & : impeller speed & $\left(\mathrm{s}^{-1}\right)$ & a & \\
\hline$P$ & : power requirement of impeller & $(\mathrm{W})$ & b & : bridging liquid \\
\hline$R$ & : weight-basis cumulative oversize percent & $(\%)$ & $\mathrm{d}$ & : disperse medium \\
\hline & \multirow{2}{*}{\multicolumn{2}{|c|}{$\begin{array}{l}\text { volume ratio of added bridging liquid to } \\
\text { powder }\end{array}$}} & $\mathrm{p}$ & \multirow{2}{*}{$\begin{array}{l}\text { : powder } \\
\text { : suspension }\end{array}$} \\
\hline & & & s & \\
\hline & : temperature & $\left({ }^{\circ} \mathrm{C}\right)$ & & \\
\hline
\end{tabular}

\section{Nomenclature}

\section{References}

1) Sirianni, A. F., C. E. Capes and I. E. Puddington: "Recent Experience with the Spherical Agglomeration Process”, Can. J. Chem. Eng., 47, 166(1969)

2) Kawashima, Y and C. E. Capes: "An Experimental Study of the Kinetics of Spherical Agglomeration in a Stirred Vessel", Powder Technology, 10, 85(1974)

3) Endo, K. : "Eki • Eki, Ko - Ekikei Kakuhansyohidouryoku No Suitei”, Kagaku Kogaku, 20, 632(1956)

4) Nagata, S. : "Mixing”, p.64, Kodansha(1975)

5) Kagaku Kogaku Kyokai(ed.) : “Kagaku Kogaku Benran, 5th ed.", p.908, Maruzen(1988)

6) Takase, H and K. Sanami : "Power Consumption of Agitating Impeller in Uniform Coarse
Suspension with No Difference in Density between Particles and Liquid”, Kagaku Kogaku Ronbunshu, 22, 945(1996)

7) Takase, H., K. Sanami and M. Sugimoto: "Change in the Impeller Torque with the Progress of Spherical Agglomeration in an Agitated Vessel”, J. Soc. Powder Technol., Japan, 29, 269 (1992)

8) Takase, H. and M. Sugimoto : "Influence of Agglomerate Size on Drainage of Packed Bed of Coal Agglomerates" Kagaku Kogaku Ronbunshu, 15, 238 (1989)

9) Lee, D. I. : "Packing of Spheres and Its Effect on the Viscosity of Suspension", J. Paint Technol., 42, 579(1970) 